\title{
POTENCIAL DA PRODUÇÃO DE BIOGÁS A PARTIR DE EFLUENTE PRÉ- TRATADO DE ABATEDOURO DE AVES DA REGIÃO OESTE DO PARANÁ ${ }^{1}$
}

Izabel Volkweis Zadinelo², Raquel Moscardi Sereniski³ ${ }^{3}$ Raquel Borin ${ }^{4}$, Kátia Cristina Fagnani ${ }^{5}$, Dile Pontarolo Stremel $^{6}$, Luis Fernando Souza Gomes ${ }^{7}$

${ }^{1}$ Aceito para publicação, $1^{\circ}$ trimestre de 2013.

${ }^{2}$ Mestranda em Aquicultura e Desenvolvimento Sustentável pela Universidade Federal do Paraná - setor Palotina (2012-2014). Tecnóloga em Biotecnologia pela Universidade Federal do Paraná - campus Palotina (2009-2012).

${ }^{3}$ Tecnóloga em Biotecnologia.

${ }^{4}$ Engenheira Química e Especialista em Engenharia e Segurança no Trabalho.

${ }^{5}$ Engenheira Ambiental.

${ }^{6}$ Engenheiro Químico, Mestre em Engenharia Química e Doutor em Engenharia Química. Professor da Universidade Federal do Paraná - UFPR - setor Palotina.

${ }^{7}$ Químico, Especialista em Desenvolvimento e Meio Ambiente, Mestre em Engenharia Agrícola e Doutor em Agronomia. Professor da Universidade Federal do Paraná - UFPR - setor Palotina.

Palavras-chave: Efluente avícola, Biodigestor, Biogás.

\section{Resumo}

O efluente proveniente de abatedouro avícola tem grande capacidade produtora de biogás, devido a sua constituição rica em matéria orgânica. Os principais gases produzidos durante a degradação dos constituintes orgânicos são o metano, dióxido de carbono e o óxido nitroso. Um método amplamente empregado no tratamento de resíduos é a biodigestão anaeróbia para captação destes gases. Em indústrias do ramo avícola os efluentes gerados possuem a característica de elevadas cargas de óleos e graxas, sólidos suspensos, nitrogênio, fósforo, proteína e lipídios, que são os responsáveis pela alteração do $\mathrm{pH}$, dos sólidos totais, da demanda bioquímica de oxigênio, da demanda química de oxigênio (DQO), entre outros parâmetros. A caracterização físico-química das águas, efluentes industriais e também dos resíduos industriais, consiste em serviços de determinação no campo e a utilização do controle analítico de laboratório relativo aos parâmetros físico-químicos. Objetivou-se a caracterização físico-química do efluente pré-tratado para se estimar o potencial de geração de biogás, a partir da instalação de um biodigestor anaeróbico na lagoa que o recebe, de um abatedouro de 
aves da região Oeste do Paraná. Para caracterização do efluente pré-tratado e avaliação da possibilidade de instalação de um biodigestor, foram analisados os parâmetros físicoquímicos: demanda química de oxigênio, sólidos totais, sólidos voláteis, sólidos dissolvidos, sólidos fixos, sólidos suspensos, potencial hidrogeniônico, óleos e graxas, e nitrogênio amoniacal, seguindo as metodologias propostas pela APHA (1995). Os procedimentos foram realizados no Laboratório de química orgânica da Universidade Federal do Paraná - setor Palotina. As estimativas médias previstas pelo Centro para a Conservação de Energia, citadas por Brondani (2010) para o dimensionamento de propostas destinadas ao comércio de carbono mencionam uma produção de $0,35 \mathrm{~m} 3$ de metano para cada $1 \mathrm{~kg}$ de DQO de efluente avícola adicionada ao biodigestor. Se a DQO de entrada na lagoa é $2285 \mathrm{mg}$ L-1, vazão média de $260 \mathrm{~m} 3$ h-1, é possível gerar 4990,44 m3 de metano/dia. Como parâmetro para cálculo do potencial de produção, adotou-se o valor de $70 \%$ de metano na composição do biogás, logo teremos o equivalente a $7129 \mathrm{~m}^{3}$ de biogás/dia. A biodigestão anaeróbia é um dos melhores processos para o tratamento de efluentes oriundos de abatedouros, como pontos positivos do processo, pode-se citar a produção de energia, redução da matéria orgânica, diminuição de odores desagradáveis e a eliminação de patógenos.

\section{Introdução}

A indústria avícola tem um papel muito importante no desenvolvimento econômico e social de uma região. No processo de abate a água é o principal insumo natural utilizado que ao final do processo gera uma elevada vazão de efluentes (LUIZ, 2007).

$\mathrm{O}$ abate e processamento de carcaças de aves abrangem atividades de controle desenvolvidas dentro do abatedouro, desde o momento em que as aves chegam à plataforma de recepção, até a obtenção do produto final, sendo a água utilizada em diversas operações que ao final do processo tem se um volume de efluente que é proporcional à quantidade de aves abatida/dia (FIGUEIREDO, et al., 2007).

De acordo com Oliveira (2011), em média, para cada ave processada, o consumo de água pode variar de 5 a $20 \mathrm{~L}$, iniciando-se já na chegada dos animais, durante a aspersão de água sobre as aves e lavagem das gaiolas de transporte.

Os resíduos líquidos oriundos de abatedouros de aves são ricos especialmente em proteínas e lipídeos, os quais são os principais responsáveis pelas alterações dos parâmetros de controle ambientais, como o $\mathrm{pH}$, sólidos totais, demanda bioquímica de oxigênio (DBO), demanda química de oxigênio (DQO), entre outros (DORS, 2006). 
Os efluentes deste tipo de indústria contêm uma DBO elevada, grande presença de óleos e graxas, material flotável, alta concentração de sólidos sedimentáveis e sólidos suspensos, alta concentração de nitrogênio, presença de sólidos grosseiros e dissolvidos (DORS, 2006).

A quantidade e concentração dos despejos de uma determinada indústria variam dentro de amplos limites, dependendo dos processos de fabricação empregados e dos métodos de controle dos despejos. Com isto, a caracterização de efluentes é uma tarefa básica para o equacionamento adequado do problema de tratamento dos mesmos. É nessa etapa que são geradas informações quanto à composição e vazão da água residual, levando em conta a suas variações ao longo do tempo, em função das atividades responsáveis por sua geração. Com base nessas informações, podem ser adotados métodos físicos, químicos ou biológicos de tratamento dos efluentes (PAULINO, 2006).

O efluente proveniente de abatedouro avícola tem grande capacidade produtora de biogás, devido a sua constituição rica em matéria orgânica. Os principais gases produzidos durante a degradação dos constituintes orgânicos são o metano, dióxido de carbono e o óxido nitroso, que representam importante parcela dos gases promotores do efeito estufa (SUNADA, 2011).

Um método amplamente empregado no tratamento de resíduos é a biodigestão anaeróbia para captação destes gases, sendo apontada como um dos melhores processos para o tratamento de efluentes oriundos de abatedouros (GAVRILESC \& CHISTI, 2005). Como produtos resultantes destacam-se a produção de energia, redução da matéria orgânica, diminuição de odores desagradáveis e a eliminação de patógenos. A técnica pode ser definida como um processo biológico natural que ocorre na ausência de oxigênio molecular, no qual diferentes tipos de microrganismos interagem para promover a transformação de compostos orgânicos complexos em produtos mais simples, resultando, principalmente, nos gases metano e dióxido de carbono (SUNADA, 2011).

Nos processos anaeróbios a degradação da matéria orgânica envolve a atuação de microrganismos procarióticos anaeróbios facultativos e obrigatórios, cujas espécies pertencem ao grupo de bactérias hidrolíticas-fermentativas, acetogênicas produtoras de hidrogênio e metanogênicas, contendo, portanto, quatro etapas: a hidrólise, acidogênese, acetogênese e metanogênese (NASCIMENTO, 2009).

O biogás produzido pela degradação da matéria orgânica (biodigestão anaeróbia) é composto principalmente de metano e dióxido de carbono com pequenas quantidades de 
outros gases, podendo ser utilizado em diversas aplicações como, por exemplo, na geração de energia elétrica, térmica, ou gás combustível. O uso do biogás não traz somente ganhos econômicos devido à redução dos gastos com combustíveis, como também traz ganhos ambientais por meio da troca de um combustível não renovável por um renovável e redução da contribuição da atividade para o aquecimento global, pela queima dos gases considerados de maior poder nocivo (OLIVEIRA, 2011).

Objetivou-se a caracterização físico-química do efluente pré--tratado que entra na primeira lagoa de estabilização para se estimar o potencial de geração de biogás, a partir da instalação de um biodigestor anaeróbico nesta lagoa que o recebe, de um abatedouro de aves da região Oeste do Paraná.

\section{Material e Métodos}

A agroindústria de abate e processamento de aves onde foram realizadas as coletas de efluente está localizada na Região Oeste do Paraná. A capacidade de abate das aves e processamento da carne é de 500 mil aves por dia.

O sistema atual de tratamento dos efluentes do abatedouro e processamento de aves é composto por um tanque equalizador que recebe todo o efluente bruto. Considera-se efluente bruto, toda a água que foi utilizada no processo industrial, desde a recepção das aves (aspersão de água sobre elas), higienização de pisos e máquinas, lavagem das gaiolas de transporte, águas dos sistemas de resfriamento de carnes, etc., até a industrialização (termoprocessados). O efluente bruto é posteriormente bombeado para flotadores por ar dissolvido, onde são adicionados produtos químicos que agem como coaguladores e floculadores de sólidos suspensos, óleos e graxas; neste processo resulta um lodo que é raspado (posteriormente seco) e efluente líquido pré-tratado que é encaminhado para as lagoas de estabilização. São quatro lagoas: duas anaeróbicas com 4.5 metros de profundidade e volume útil de $38577 \mathrm{~m} 3$ cada, uma lagoa aerada e uma de decantação e polimento final.

Nas lagoas de estabilização são utilizados produtos comerciais biotecnológicos, licenciados pelo IBAMA, para tratamento de efluentes industriais, considerados como remediadores, sendo que um produto atua na degradação de Óleos e Graxas (OeG), Demanda Química de Oxigênio (DQO) e Demanda Bioquímica de Oxigênio (DBO) a base de um micro-organismo selecionado (não patogênico, degradador de matéria orgânica), e outro que tem atividade bioestimulante. 
Após o tratamento descrito o efluente está pronto para ser lançado no corpo receptor. O corpo receptor da Indústria classifica-se como um Rio da Classe 2, de acordo com a Resolução CONAMA no 357/05.

Apesar de ser um sistema eficiente de acordo com a agroindústria, e dados de análises coletadas pelo IBAMA, ressalta-se que a instalação de um biodigestor para a captação dos gases eliminados nas lagoas anaeróbicas, seria uma oportunidade de geração de energia, economizando-se em madeira queimada em caldeiras para geração de vapor utilizado no processamento das aves própria agroindústria. Desta forma evitar-se-ia a eliminação de gases causadores do efeito estufa pelas lagoas, tendo-se um retorno econômico e ambiental.

Para caracterização do efluente pré-tratado, foram analisados os seguintes parâmetros físico-químicos: demanda química de oxigênio (DQO), sólidos totais (ST) sólidos totais voláteis (STV), sólidos totais dissolvidos (STD), sólidos totais fixos (STF), sólidos suspensos (SS), potencial hidrogeniônico $(\mathrm{pH})$, óleos e graxas (OG), e nitrogênio amoniacal total (NAT), seguindo as metodologias propostas pela APHA (1995). Os procedimentos foram realizados no Laboratório de Química Orgânica da Universidade Federal do Paraná - setor Palotina. Foram aferidos também a temperatura, a vazão e o tempo de retenção hidráulica (TRH) do efluente na lagoa que recebe o efluente pré-tratado.

Foram realizadas cinco coletas do efluente pré-tratado do abatedouro de aves, na entrada da primeira lagoa do sistema de tratamento biológico existente, no período de abril a junho de 2012. Em cada coleta as amostragens do efluente foram compostas (durante quatro horas, coletado uma vez por hora), de volume pré-estabelecido (200 mL por vez), totalizando $800 \mathrm{~mL}$ de amostra do efluente bruto que entra na primeira lagoa de estabilização. As análises físico-químicas eram realizadas no mesmo dia da coleta.

Após obterem-se os resultados da caracterização físico-química, calculou-se o potencial de geração de biogás a partir do efluente, visando à instalação de um biodigestor anaeróbico, nas condições físico-químicas atuais do sistema da agroindústria.

\section{Resultados e Discussões}

Os métodos de tratamento de efluentes industriais estão diretamente associados ao tipo de efluente gerado, ao controle operacional da indústria e às características da água utilizada (MENDES, 2005). A instalação de equipamentos ou inserção de processos de biodegradação irão reduzir significativamente o tamanho, o capital e os custos de operação de uma planta de tratamento biológico por lagoas de estabilização pela significativa redução da 
carga poluidora através de degradação de sólidos suspensos (SS) e óleos e graxas (OG) do efluente (GIORDANO, 2005).

Na tabela 1 estão dispostos os resultados parâmetros avaliados do efluente bruto que entra na primeira lagoa de estabilização do sistema utilizado na agroindústria.

TABELA 1. Valores médios dos parâmetros avaliados seguidos pelos respectivos desvios padrão.

\begin{tabular}{|c|c|}
\hline Parâmetros avaliados & Valores obtidos na caracterização \\
\hline $\mathrm{DQO}\left(\mathrm{mg} \mathrm{O}_{2} \mathrm{~L}^{-1}\right)$ & $2285 \pm 145$ \\
\hline $\mathrm{DBO}_{5}\left(\mathrm{mg} \mathrm{O}_{2} \mathrm{~L}^{-1}\right)$ & $1150 \pm 109$ \\
\hline NAT $\left(\mathrm{mg} \mathrm{L}^{-1}\right)$ & $30 \pm 3,05$ \\
\hline $\mathrm{OG}\left(\mathrm{mg} \mathrm{L}^{-1}\right)$ & $582 \pm 82$ \\
\hline $\mathrm{ST}\left(\mathrm{g} \mathrm{L}^{-1}\right)$ & $0,99 \pm 0,02$ \\
\hline $\operatorname{STV}\left(\mathrm{g} \mathrm{L}^{-1}\right)$ & $0,60 \pm 0,16$ \\
\hline $\operatorname{STF}\left(\mathrm{g} \mathrm{L}^{-1}\right)$ & $0,39 \pm 0,16$ \\
\hline $\operatorname{STD}\left(\mathrm{g} \mathrm{L}^{-1}\right)$ & $0,83 \pm 0,01$ \\
\hline $\mathrm{SS}\left(\mathrm{g} \mathrm{L}^{-1}\right)$ & $0,16 \pm 0,01$ \\
\hline $\mathrm{pH}$ & $6,0 \pm 0,2$ \\
\hline Temperatura $\left({ }^{\circ} \mathrm{C}\right)$ & $24,5 \pm 1,5$ \\
\hline Vazão $\mathrm{m}^{3} \mathrm{~h}^{-1}$ & $260 \pm 30$ \\
\hline TRH (dias) & $6,7 \pm 0,3$ \\
\hline
\end{tabular}

Os SS e OeG no efluente usualmente contribuem para 30 a $70 \%$ da DBO total na água. Portanto, sua remoção efetiva pode diminuir a DBO da água em percentagem relativamente iguais, desse modo reduzindo o tamanho e os custos operacionais da planta de tratamento biológico secundário. Isto tem um impacto significativo nos custos, durante o ciclo total de vida da planta (SCHOENHALS, 2006).

Como alternativa para a agroindústria de processamento e abate de aves, visando à redução do impacto ambiental e à recuperação de energia e nutrientes contidos no efluente de abatedouros avícolas, sugeriu-se a biodigestão anaeróbia, que demonstra ser um eficiente sistema de tratamento e reciclagem, uma vez que os nutrientes contidos no efluente garantem a sobrevivência e reprodução dos micro-organismos presentes durante o processo, permitindo que ocorra a degradação da fração orgânica não estável e, portanto, poluente, até a forma estável (OLIVEIRA, et al., 2011).

A faixa de pH de operação dos biodigestores é entre 6,0 e 8,0, sendo que alguns autores (RIGO, 2004; SCHOENHALS, 2006), ao realizarem a biodigestão de efluentes de abatedouro, obtiveram valores médios que variaram de 6,7 a 7,9. Desta forma podemos observar que o $\mathrm{pH}$ do efluente que entra na lagoa 1 esta na faixa ideal ou próximo tendo um valor médio de 6. 
A produção de biogás é estimada, entre outros fatores, pela temperatura de operação do biodigestor, sendo que nos Estados do Sul a faixa de temperatura da biomassa situa-se entre 20 e $25^{\circ} \mathrm{C}$ (OLIVEIRA, 2005). Sendo assim, pode-se considerar que as bactérias predominantes na digestão anaeróbia, que ocorre no biodigestor, são predominantemente as mesofílicas, cuja faixa de temperatura situa-se entre 20 e $45^{\circ} \mathrm{C}$, estando a temperatura do efluente pré-tratado dentro da faixa adequada.

Vários autores apresentam que os melhores resultados de potenciais de produção de biogás e reduções de DQO ocorreram em torno de 7 a 10 dias de retenção do efluente de abatedouros de aves nos biodigestores, e por isso este parece um tempo de retenção hidráulica (TRH) satisfatório. No entanto, sabe-se que o TRH a ser adotado deve ser fundamentado, principalmente, na carga orgânica contida no afluente, já que este seria um tempo necessário para que esta carga fosse degradada ao máximo possível (SANCHEZ, et al., 2005). O tempo de retenção atual na lagoa 1 é de 6,7 dias, com carga de DQO na entrada de $2285 \mathrm{mg} \mathrm{L}^{-1}$, e vazão média de $260 \mathrm{~m}^{3} \mathrm{~h}^{-1}$.

O pré-tratamento também contribui para um processo biológico mais eficiente. As bactérias são mais efetivas na digestão da matéria dissolvida. Segundo Sunada (2011), o desempenho do processo de biodigestão muitas vezes pode ser retardado ou prejudicado devido ao acúmulo de gorduras e sólidos flutuantes no biodigestor, que levam a uma redução da atividade metanogênica e da biomassa e ainda danos operacionais como o entupimento do sistema, sendo, portanto importante à separação desta fração para melhor resposta dos reatores. Pode-se concluir que é possível conciliar o processo de flotação antes de um processo de biodigestão, não necessitando de mudanças no processo atual da agroindústria.

É a porcentagem de metano que confere ao biogás um alto poder calorífico, que varia de 5000 a $7000 \mathrm{kcal} \mathrm{m}^{3}$. Esta variação decorre de sua maior ou menor pureza, ou seja, maior ou menor quantidade de metano (BARRERA, 2003).

As estimativas médias previstas pelo CCE (Centro para a Conservação de Energia), citadas por Brondani (2010) para o dimensionamento de propostas destinadas ao comércio de carbono mencionam uma produção de $0,35 \mathrm{~m} 3$ de metano para cada $1 \mathrm{~kg}$ de DQO de efluente avícola adicionada ao biodigestor. Se a DQO de entrada é $2285 \mathrm{mg} \mathrm{L}-1$, e vazão média de 260 m3 h-1 (sendo $6240 \mathrm{~m} 3$ dia-1), logo temos:

- DQO $2,285.10^{-3} \mathrm{~kg} \mathrm{~L}^{-1}$

- Vazão $6240 \mathrm{~m}^{3}$ dia $^{-1}$ é igual a $6240000 \mathrm{~L}$ de efluente por dia.

- Multiplicando DQO pela vazão em litros $=142584 \mathrm{~kg} \mathrm{dia}^{-1}$ 
- Multiplicando por $0,35 \mathrm{~m}^{3}$ de metano por $\mathrm{kg}^{-1}$ de DQO adicionada' é possível gerar $4990,44 \mathrm{~m}^{3}$ de metano por dia.

Segundo testes realizados por Sunada (2011) e Oliveira (2011) com efluentes avícolas, as porcentagens de metano no biogás podem situar-se 69-75\% e 66-70\% respectivamente. Como parâmetro para cálculo do potencial de produção, adotou-se o valor de $70 \%$ de metano na composição do biogás, logo teremos o equivalente a $7129 \mathrm{~m}^{3}$ de biogás/dia.

Um metro cúbico de biogás (70\% de metano) equivale a (BARRERA, 2003 \& GALBIATTI, 2010):

- $\quad 0,613$ L de gasolina;

- $\quad 0,553$ L de óleo diesel;

- 0,454 L de gás de cozinha;

- $1,536 \mathrm{~kg}$ de lenha;

- $1,428 \mathrm{Kw}$ de eletricidade;

- $\quad 0,455 \mathrm{~kg}$ de carvão;

- $0,6 \mathrm{~m}^{3}$ de gás natural;

Dessa forma, em termos de demonstração, poder-se-ia gerar, por exemplo, aproximadamente $10180 \mathrm{kw}$ de energia elétrica por dia, ou economizar $10950 \mathrm{~kg}$ de lenha (cavacos) utilizados nas caldeiras por dia.

A biodigestão anaeróbia é apontada como um dos melhores processos para o tratamento de efluentes oriundos de abatedouros, podendo-se citar a produção de energia, redução da matéria orgânica, diminuição de odores desagradáveis e a eliminação de patógenos.

\section{Conclusão}

Pela caracterização físico-química do efluente pré-tratado observa-se que é possível à instalação de um biodigestor para captação de gases, com redução do impacto ambiental, recuperação de energia e nutrientes contidos no efluente, e produção de biogás para utilização no processo de abate e processamento de aves pela agroindústria. 


\section{Referências Bibliográficas}

1. AMERICAN PUBLIC HEALTH ASSOCIATION - APHA. Standard methods for examination of water and wastewater. 21. ed. Washington: American Water Works Association, 2005. 1368p.

2. BARRERA, P.; Biodigestores; Revista Energia, fertilidade e saneamento para a zona rural. Editora Ícone, $2^{a}$ ed, São Paulo, 2003.

3. BRASIL. CONAMA (Conselho Nacional do Meio Ambiente). Resolução n.357, de 17 de março de 2005.

4. BRONDANI, J. C.. Biodigestores e biogás: balanço energético, possibilidades de utilização e mitigação do efeito estufa. 2010. 118 f. Dissertação (Mestrado em Engenharia de produção). Universidade Federal de Santa Maria, Rio Grande Sul, 2010.

5. DORS, G.; Hidrólise enzimática e biodigestão de efluentes da indústria de produtos avícolas; 2006, 101 F; Dissertação (mestrado em Engenharia Química: Desenvolvimento de Processos Químicos e Biotecnológicos) Universidade Federal de Santa Catarina; Florianópolis, SC, 2006;

6. FIGUEIREDO, E. A. P., et al.; Recomendações técnicas para a produção, abate, processamento e comercialização de frangos de corte coloniais; Embrapa Suínos e Aves; Sistemas de Produção, no 3, 2007;

7. GALBIATTI, J. A.; Estudo quali-quantitativo do biogás produzido por substratos em biodigestores tipo batelada. Revista Brasileira de Engenahria Agrícola Ambiental, v.14, n.4, p.432-437, 2010.

8. GAVRILESCU, M. \& CHISTI, Y.; Biotechology sustainable alternative for chemical industry. Revista Biotechnology Advances. V. 23, p. 471-499, 2005.

9. GIORDANO, G.; Tratamento e controle de efluentes industriais. 2005, $81 \mathrm{f}$; Departamento de Engenharia Sanitária e do Meio Ambiente - Universidade do Estado do Rio de Janeiro, 2005.

10. LUIZ, D. de B; Gerenciamento hídrico em frigoríficos; 2007, 115 f; Dissertação (mestrado em Engenharia Química: Desenvolvimento de Processos Químicos e Biotecnológicos); Universidade Federal de Santa Catarina; Florianópolis, SC, 2007;

11. MENDES, A. A., et al.; Aplicação de lipases no tratamento de águas residuárias com elevados teores de lipídeos; Revista Quimíca Nova, Vol. 28, Nº . 2, p. 296-305, 2005;

12. MENEGAZ, R. C., et al.; Remoção físico-química de fósforo por floco-sedimentação aplicada ao pós-tratamento de efluente de abatedouro avícola; Revista Ciências Exatas e Naturais, Vol.13, no.2, 25 p; 2011;

13. NASCIMENTO, R. do; Estudo da cinética de biodegradação de efluente com alta concentração de ácidos graxos; 2009, 99 f; Dissertação (Engenharia Química: Desenvolvimento de Processos); Centro de Engenharias e Ciências Exatas; Universidade Estadual do Oeste do Paraná, Toledo, PR, 2009;

14. OLIVEIRA, A. B. M., et al.; Biodigestão anaeróbia de efluente de abatedouro avícola; Revista Ceres, Viçosa, v. 58, nº 6, p. 690-700, 2011;

15. OLIVEIRA, P. A. V. de. Projeto de biodigestores e estimativa de produção de biogás em sistema de produção. Concórdia: Embrapa Suínos e Aves, 2005. 8p. (Embrapa Suínos e Aves. Comunicado Técnico, 417).

16. PAULINO, C. Z.; Produção de biomassa por Rubrivivax gelatinosus em efluente de abatedouro avícola utilizando métodos industriais. 2006, 75 f.; Dissertação (mestrado em Medicina Veterinária) Universidade Estadual Paulista "Júlio de Mesquita Filho" (UNESP), Araçatuba, SP, 2006.

17. RIGO E. Aplicação de lipases como auxiliar no pré-tratamento de efluentes de frigoríficos de suínos e bovinos. 2004. 84 f. Dissertação (Mestrado em Engenharia de 
alimentos); Departamento de ciências agrárias, Universidade Regional integrada do alto Uruguai e das missões, Erechim, RS, 2004.

18. SANCHEZ, E.; et al.; Effect of organic loading rate on the stability, operational parameters and performance of a secondary up flow anaerobic sludge bed reactor treating piggery waste. Revista Bioresource Technology, v.96, p.335-344, 2005.

19. SCHOENHALS, M.; SENA, R. F.; JOSÉ, H. J.; Avaliação da eficiência do prosesso de coagulação/flotação aplicado como tratamento primário de efluentes em abatedouro de frangos; Revista Engenharia ambiental - Espirito Santo do Pinhal, v. 3, no 2, p. 05 024; 2006;

20. SUNADA, N. S.; Efluente de abatedouro avícola: processos de biodigestão anaeróbia e compostagem; 2011, 87 f; Dissertação (mestrado em Zootecnia); Faculdade de ciências agrárias; Universidade Federal da Grande Dourados; Dourados, MS, 2011; 